\title{
Cigarette Smoking Cessation
}

\author{
M. Mujahid Salim, M.D.*, Amatal B. Mir, M.B. \\ Jamaica, New York
}

DOI: http://dx.doi.org/10.5915/21-4-13513

\begin{abstract}
Despite two decades of health warnings and numerous clinical reports concerning the negative health consequences of cigarette smoking, smoking cessation programs continue to have only limited success. Reviewed are the effects of tobacco smoking, morbidity and mortality patterns among smokers, and methods and success rates of several smoking cessation strategies.
\end{abstract}

Key words: Cigarettes, smoking cessation, tobacco health effects.

The use of tobacco was originally limited to the native American Indians and was introduced into Europe by Christopher Columbus in the 15th century. Pope Innocent $\mathrm{X}$ excommunicated smokers while King James I had them executed.' The beginning of this century saw the development of automated cigarette manufacturing; from that time on cigarettes replaced chewing tobacco and snuff. During World War I cigarettes were provided to the American soldiers and were associated through marketing with bravery and patriotism. In the $1930 \mathrm{~s}$ smoking was extensively advertised and was suddenly in vogue. There were, however, increasing concerns about the ill effects of smoking. The issue reached a climax with the Surgeon General declaring it a health hazard sufficient to warrant appropriate remedial action. The annual cost for medical care, absenteeism,

From the Department of Medicine

Pulmonary Medicine Section

Queens Hospital Center Affiliation

Long Island Jewish Medical Center and School of Medicine Health Science Center

State University of New York at Stony Brook, New York

Reprint Requests: M. Mujahid Salim, M.D.

Queens Hospital Center

Pulmonary Medicine Division

82-68 164th Street

Jamaica, New York 11432 decreased productivity and accidents in the U.S. was estimated to be more than $\$ 30$ billion. $^{2}$ The American Association for Cancer Research now puts this figure at $\$ 80$ billion. Despite the Surgeon General's warnings, the American tobacco industry has increased its production by $140 \%$ and is spending more than $\$ 2$ billion in advertisements. ${ }^{3}$ The estimated tobacco revenues are $\$ 60$ billion, including industry related jobs, and federal, state and local taxes. ${ }^{4}$ In 1982 , the Surgeon General attributed $30 \%$ of all cancer deaths to tobacco use, which approximated 135,000 deaths in 1983. Of these, 110,000 resulted from lung cancer while the remainder were due to cancer of the larynx, oral cavity, esophagus, kidney, bladder and pancreas.' Lung cancer was a rare illness early in the twentieth century but increased during the 1950s, reflecting the increase in cigarette smoking. (Table 1)

Components of tobacco and their systematic effects

There are more than 3,000 components in cigarette smoke. The most toxic product is tar, which has been proven to contain carcinogens, tumor promoters and initiaters, and mutagens. Nicotine is the most active compound in tobacco smoke. The large absorptive surface of the lung allows rapid distribution in the systemic circulation and central nervous system. Seven seconds after inhalation, $25 \%$ of the available nicotine is delivered to the brain while $75 \%$ is delivered to the rest of the body, were nicotine stimulation of the autonomic nervous system 
Table 1

Prevalence of cigarette smoking according to race, sex and age; 1965, 1976, 1980, 1983.*

A. MALES

\begin{tabular}{lllllllll}
\hline $\begin{array}{l}\text { Age } \\
\text { (Years) }\end{array}$ & \multicolumn{4}{c}{ White } & \multicolumn{4}{c}{ Black } \\
$20-44$ & 1965 & 1976 & 1980 & 1983 & 1965 & 1976 & 1980 & 1983 \\
\hline $45+$ & 58.5 & 46.8 & 41.4 & 38.8 & 67.7 & 57.4 & 47.9 & 41.8 \\
\hline & 44.4 & 35.0 & 32.4 & 30.1 & 52.3 & 42.3 & 42.2 & 42.9
\end{tabular}

B. FEMALES

\begin{tabular}{lllllllll} 
Age & \multicolumn{4}{c}{ White } & \multicolumn{4}{c}{ Black } \\
Years & 1965 & 1976 & $\mathbf{1 9 8 0}$ & $\mathbf{1 9 8 3}$ & $\mathbf{1 9 6 5}$ & $\mathbf{1 9 7 6}$ & $\mathbf{1 9 8 0}$ & $\mathbf{1 9 8 3}$ \\
$20-44$ & 43.3 & 36.8 & 33.3 & 34.3 & 45.0 & 40.1 & 34.3 & 36.2 \\
\multicolumn{1}{|c|}{$45+$} & 25.1 & 26.7 & 25.5 & 23.6 & 20.6 & 28.3 & 25.6 & 28.1
\end{tabular}

*Smoking and Health: A National Status Report reference number modified form.

occurs. $^{6}$ The amount of nicotine in mainstream smoke which would be absorbed from rapidly smoking one and a half packs of cigarettes would constitute a fatal dose in humans.

Anorexic effects and chronic stimulation of the basal metabolic rate may contribute to weight control. Smoking has thus become popular with young weight-conscious women. The half-life of nicotine in the blood is 40 minutes, which parallels the urge to smoke experienced by heavy smokers.

The acute effects of nicotine include increased myocardial contraction, oxygen consumption, excitability and coronary blood flow. Chronic effects include tachycardial, systolic and diastolic hypertension, and increased artherogenesis.

Carbon monoxide is also a product of combustion and forms carboxyhemoglobin in the blood. This lowers the oxygen carrying capacity and decreases exercise tolerance, precipitating attacks of angina in patients with ischemic heart disease.

\section{Morbidity and mortality pattern among smokers}

The association of cigarette smoking with cancer has already been described. In 1983, 62,000 deaths were ascribed to chronic lung disease. (Table 2) Up to $90 \%$ of smokers have been shown to have chronic obstructive pulmonary disease (COPD) at autopsy. Cigarette related cardiovascular disease has been estimated to account for $25 \%$ of all cardiovascular deaths, or 170,000 deaths, in $1983 .^{*}$

Smoking during pregnancy may cause vaginal bleeding, placental abruption and amnionitis. Spontaneous abortion is $30-70 \%$ higher in pregnant women who smoke than in non-smokers, and rates of fetal death after gestation of 28 weeks are also significantly higher, as are premature births and low birth weight infants. ${ }^{9}$

Involuntary smoke inhalation affects three out of four Americans, resulting in local irritant effects, headache, cough, nasal and eye irritation, impaired pulmonary function, and malignancies. ${ }^{10-12}$ Children are affected with more frequent respiratory illnesses, respiratory symptoms, and pneumonia. ${ }^{13-14}$ Statistically, 30 to 35 year old smokers who smoke 10-20 cigarettes per day will die five years earlier than non-smokers, while a one to two pack a day smoker will die $61 / 2$ years earlier. It is estimated that every cigarette smoked reduces one's life span by $5 \frac{1 / 2}{2}$ minutes.

In spite of these data, people continue to smoke because the serious personal consequences seem remote. The Tobacco Institute has spread the erroneous inpression that scientists are evenly split as to the dangers of smoking. The tobacco industry has also reduced the tar and nicotine content in cigarettes by $50 \%$ to counter bad publicity, and has made cigarettes one of the most heavily promoted products in the world. ${ }^{13}$ Time and Newsweek magazines, for example, receive in excess of $\$ 30$ million a year from cigarette advertising. ${ }^{16}$

\section{Smoking cessation}

A drug is defined as "dependency producing" if its removal produces a withdrawal state, which nicotine does. If an individual suddenly stops the use of tobacco he may experience any one of the following symptoms: craving for tobacco, increased anxiety, irritability and restlessness, difficulty in concentrating, headache, drowsiness and gastrointestinal disturbances. ${ }^{17}$ The intensity is worst during the first two or three days, decreasing over the next week and decreasing again over the next two weeks..$^{18-19}$ Heart rate and diastolic blood pressure decrease within six hours of withdrawal, an effect which can last from three to thirty days..$^{18}$ Decreased wakefulness, weight gain and other psychophysiologic changes also may 
Pathologic changes and manifestations of lung injury by cigarette smoke.*

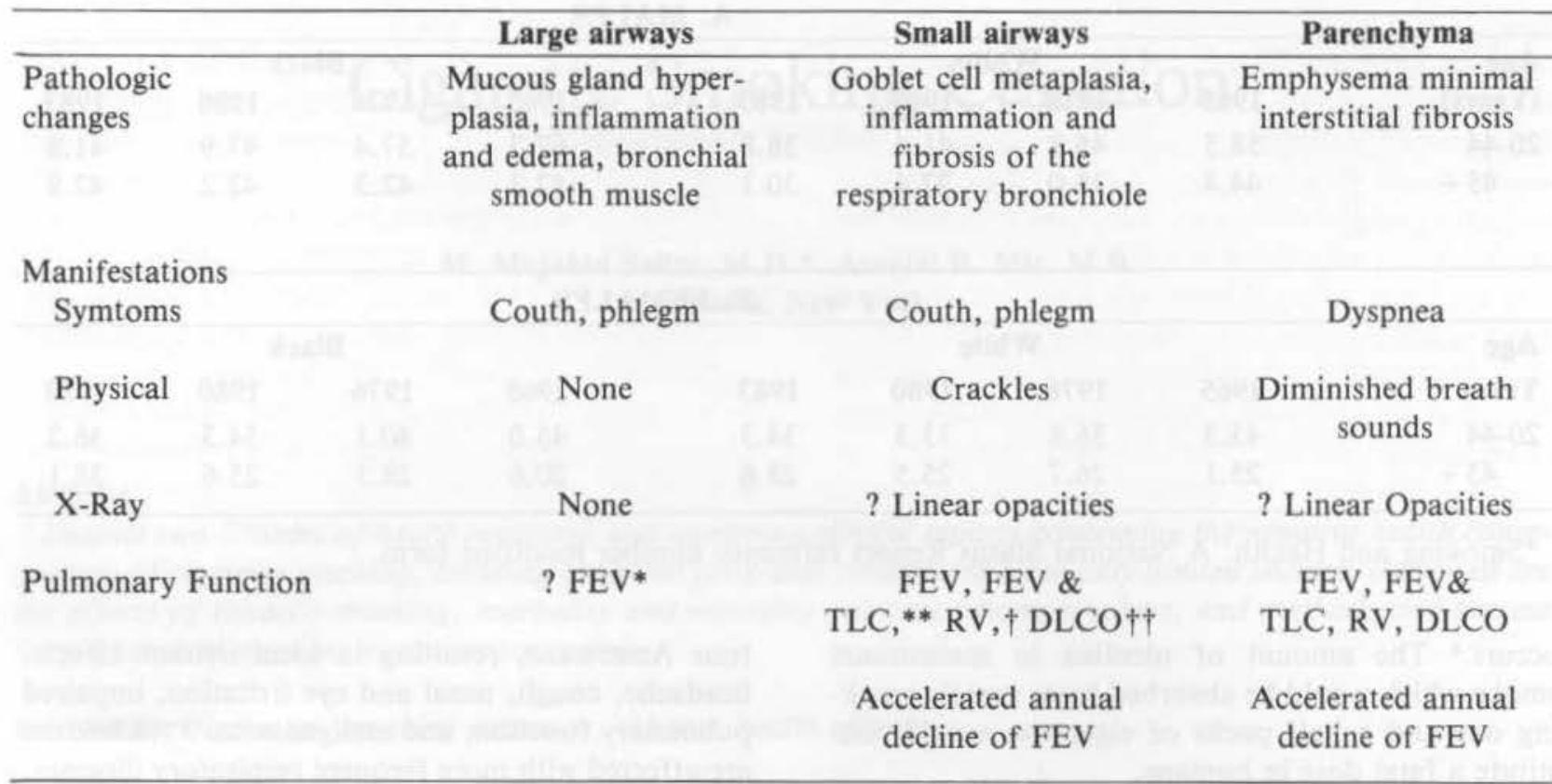

The Health Consequences of Smoking: A Report of the Surgeon General 1985

*FEV: Forced expiratory volume in one second

**TLC: Total lung capacity

†RV: Residual volume

††DLCO: Diffusion of carbon monoxide

occur. If a moderate smoker stops smoking at age 65 , he will regain two years of his life; a heavy smoker will regain four years. ${ }^{20}$ The cancer related death rate is cut in half $2 \frac{1 / 2}{2}$ years after smoking cessation; the death rate from coronary heart disease drops by $25 \% .^{21-22}$ People who quit smoking also have a lower rate of duodenal ulcer recurrence than those who do not. ${ }^{23}$

Physicians have been shown to have a $20 \%$ success rate in achieving smoking cessation among their patients. Initially, this may seem discouraging, but actually it is a large figure considering the number of people who smoke.

Other cessation programs report higher success rates - up to $70 \%$ initially, but four out of every five of these short term quitters resume smoking by the end of two years. Only $20 \%$ of pregnant women who smoke actually stop. Most people quit because they are suffering from some serious consequence of smoking, or because they have finally responded to medical warnings.

Summary of smoking cessation strategies.

1. Aversive conditioning techniques

A. Electric Shock Therapy has not proven to be effective. ${ }^{25}$

B. Rapid Smoking Therapy consists of a patient's inhaling smoke from his cigarette every six seconds until he no longer desires another puff, which generally occurs within fifteen minutes. ${ }^{26-2 n}$ Smoking cessation rates as high as $60 \%$ have been reported with this technique..$^{29-30}$

2. Self help manuals

The American Lung Association has published several books on cigarette cessation. The one year cure rate of patients who try to quit by using these publications is estimated to be $5 \%$. $^{31}$

3. Hypnosis

Success rates as high as $45-85 \%$ have been claimed with this technique, but no controlled studies have been published. ${ }^{32-35}$

4. Acupuncture

Success rates of up to $50 \%$ are reported, ${ }^{36}$ but controlled studies suggest only a $10 \%$ success rate. This technique reduces the desire for nicotine, supposedly by releasing neuropeptides.

5. Cessation aids

Filters and water pipes reduce tar, nicotine, and carbon monoxide, and wean the tobacco users in 
stages. These aids have not been proven better than the "cold turkey" quitting approach.

6. Drug treatment

Nicotine containing chewing gum was first developed 20 years ago in Sweden and is now commercially available in the United States. Each piece of gum contains $2 \mathrm{mg}$ of nicotine which is twice the amount in an average cigarette. Ninety percent of nicotine is released within 20-30 minutes, depending upon the rapidity of chewing, thus keeping the blood concentration just high enough to satisfy the smoker. If chewed too rapidly toxicity occurs. Local toxic effects include irritation and anaesthesia of the mouth and a sore throat. Systemic toxic effects include light headedness, hiccups, nausea, diaphoresis, diarrhea, excessive salivation, abdominal pain, vomiting, mental confusion and alteration in hearing. Contraindications to the use of nicotine gum include pregnan$\mathrm{cy}$, severe angina and significant temporomandibular disease. Hypertension, gastroduodenal irritation, arrhythmias, hyperthyroidism and exacerbation of diabetes mellitus have been listed as complications. Up to 12 pieces of the gum per day may be used safely. It is recommended that gum use be continued for two to three months, reduced over the next three months, and finally tapered off over another three to six months. Up to a $38 \%$ success rate has been achieved with the use of nicotine gum. ${ }^{37}$ Cigarette smoking impedes myocardial oxygen delivery far more severely than nicotine gum.

\section{Conclusion}

The magnitude of the smoking problem is overwhelming and the annual mortality and expense are staggering. Millions of Americans have stopped smoking, although the worldwide incidence of smoking is rising by $1 \%$ annually. Generalized awareness is necessary to control this epidemic, which undermines the basic rights of consumers.

Finally; Prophet Muhammad (PBUH) said:

"Avoid all addicting substances."

And Allāh says:

". . . and do not by your own hands destroy yourselves. . . ", 43

\section{Reference}

1. Jackson FN, Holle RHO: Primary Care 1955; 12(2):197-216.

2. Weis W: Before you hire smokers. Presented at the annual meeting of FANS (Fresh Air for Nonsmokers), 1981.

3. Federal Trade Commission: Report to Congress pursuant to federal cigarette labeling and advertising Act. Washington, D.C., Federal Trade Commission, 1983.
4. Repace JL, Lowery $\mathrm{H}$ : Indoor air pollution, tobacco smoke, and public health. Science 1980; 208:464-472.

5. U.S. Public Health Service: The health consequences of smoking - chronic obstructive lung disease. Rockville, Maryland, U.S. Dept. of Health and Human Services, Office of Smoking and Health, 1984.

6. Russell MAH, Feyerabend C, Cole PV: Plasma nicotine levels after cigarette smoking and chewing nicotine gum. British Medical Journal 1976; 1:1043-1046.

7. U.S. Surgeon General: The health consequences of smoking cancer. A report of the surgeon general. Rockville, Maryland, U.S. Dept. of Health and Human Services, 1982.

8. U.S. Public Health Service: The health consequences of smoking - cardiovascular disease. Rockville, Maryland, U.S. Dept. of Health and Human Services, Office of Smoking and Health, 1983.

9. U.S. Public Health Service: The health consequences of smoking for women. Rockville, Maryland, U.S. Dept. of Health and Human Services, Office of Smoking and Health, 1980.

10. Trichopoulos D, et al: Lung cancer and passive smoking Int. J. Cancer 1981; 177:1-4.

11. Garfinkel L: Time trends in lung cancer mortality among non-smokers and a note on passive smoking JNCI 1981; 66:1061-1064.

12. Kauffman F, Perrizet: Effect of passive smoking on respiratory function. Eur J Respir Dis (suppl LB) 1981 ; 62:109-112.

13. Weiss ST, Tager IB, et al: The effects of involuntary smoking. Am Rev Respir Dis; 128:933-936.

14. Lefcoe $N$, et al: The health risks of passive smoking Chest 1984; 84:90-93.

15. Rickert WS: Less hazardous cigarettes: Fact or fiction? NY State J Med 1983; 1269-1273.

16. Imperato PJ, Mitchell G: Cigarette smoking: A "chosen" risk. NY State J of Medicine 1986 84:485-489.

17. American Psychiatric Association: Diagnostic Statistical Manual of Mental Disorders. Edition 3, Washington, D.C., APA, 1981; pp. 159-176.

18. Shiffman SM: The tobacco withdrawal syndrome. In: Kansnegor NA (ed). Cigarette Smoking Dependency Process. Rockville, Maryland: National Institute on Drug Abuse Research Monograph, 23, 1979.

19. Shiffman SM, Jarvil ME: Smoking withdrawal symptoms in two weeks of abstinence. Psychopharmacology; 50:35-39.

20. Rogot E: Smoking and life expectancy among U.S. veterans. Am J Pub Health 1978; 68:1023-1025.

21. Doll R, Hill AB: Mortality in relation to smoking: Ten years observation of British doctors 
(Part I). Br Med J 1964; 1:1023-1025.

22. Doll R, and Hill AB: Mortality in relation to smoking and recurrence of duodenal ulcer. $\mathrm{N}$ Engl J Med 1984; 311:689-693.

23. Sontag S, Gaham DY, Belsito A, Opekun A, et al: Cimetidine, cigarette smoking and recurrence of duodenal ulcer. $N$ Engl J Med 1984; 311:689-693.

24. Anda RF, Remington PL, et al: Are physicians advising smokers to quit? JAMA 1987; 257:1916-1919.

25. Huber G, Burke M, Nett L: Smoking cessation. Sem Resp Med 1986; 147-157.

26. Hall R, Sachs DLP, and Hall SK: Medical risk and therapeutic effectiveness of rapid smoking. Behav Ther 1979; 10:249-259.

27. Hall RG, Sachs DLP, Hall SM, Benowits NL: Two-year efficiency and safety of rapid smoking therapy in patients with cardiac and pulmonary disease. J Consult Clin Psychol 1984; 52:574-581.

28. Sachs DPL, Hall RG, and Hall SM: Effects of rapid smoking: Physiologic evaluation of a smoking-cessation therapy. Ann Intern Med 1978; :639-641.

29. Lichtenstein E, Harris DE, Birchler GR, Wahl JM, Schanahl DP: Comparision of rapid smoking, warm smoking air, and attention placebo in the modification of smoking behavior. J Consult Clin Psychol 1973; 40(1):92-98.

30. Schmalh DO, et al: Smoky air and rapid smoking. J Consult Clin Psychol 1972; 27:46-55.

31. Davis AL, Faust R, Ordentlich M: Self-help smoking cessation and maintenance programs: A comparative study with 12-month follow-up by the American Lung Association. Am J Publ Health $1984 ; 74: 1212-1217$.
32. Agee LL: Treatment procedures using hypnosis in smoking cessation programs: A review of the literature. J Am Soc Psychol Dent Med 1983; 30:111-126.

33. Berkowitz B, Ross-Townsend A, and Hohberger R: Hypnotic treatment of smoking: The singletreatment method revisited. Am J Psychiatry $1979 ; 136: 83-85$.

34. Spiegel H: A single-treatment method to stop smoking using ancillary self-hypnosis. Int J Clin Exp Hypn 1970; 28:235-249.

35. Watkins HH: Hypnosis and smoking: A five session approach. Int J Clin Exp Hypn 1976; 24:381-390.

36. Choy DSJ, Lutzker L, and Meltzer L: Effective treatment for smoking cessation. Am J Med 1983; 75:1033-1036.

37. Fagerstrom KO: A comparison of psychological and pharmacological treatment in smoking cessation. J Behav Med 1982; 5:343-351.

38. Fisher EB, Rost K: Smoking cessation: A practical guide for the physician. Clinics in Chest Med 1986; 337-362.

39. International Organization of Consumers Unions: Giving a voice to the world's consumers. The Hague, Netherlands, International Organization of Consumers Unions, 1984.

40. Not the smoker, but the tobacco industry. ICOI Newsletter 1985; 143 (May-June): pp. 1-2.

41. Dying for a smoke. Consumer Interpol Focus, No. 10 , Dec. 1984 , pp. 2-3.

42. Royal College of Physicians of London: Smoking or Health. The Third Report of the Royal College of Physicians of London. London, Pitman Medical, 1978.

43. Glorious Qur'ān: Chapter 2, Verse 195. 